\title{
Volume change in compacted claystone-bentonite mixture as affected by the swamp acidic water
}

\author{
Yulian Firmana Arifin, ${ }^{\mathrm{a}, \mathrm{b}}$, Muhammad Arsyad ${ }^{\mathrm{b}}$, Jeane Monica ${ }^{\mathrm{b}}$, Setianto Samingan Agus ${ }^{\mathrm{c}}$ \\ ${ }^{a}$ Professional Engineer Education Study Program, Lambung Mangkurat University, Banjarbaru 70714, Indonesia \\ ${ }^{b}$ Civil Engineering Study Program, Lambung Mangkurat University, Banjarbaru 70714, Indonesia \\ ${ }^{c}$ Mott MacDonald Singapore Pte. Ltd., Singapore 239693, Singapore
}

Article history:

Received: 12 September 2021 / Received in revised form: 30 November 2021 / Accepted: 4 December 2021

\begin{abstract}
Water containing sulfuric acid with a $\mathrm{pH}$ up to 3 is prevalent in swampy areas. This article focuses on the effects of the solution on volume change of compacted claystone-bentonite mixture. Claystone was obtained from Banjarbakula landfill and it was mixed with bentonite on a 5, 10,15 , and $20 \%$ dry mass basis. Samples possessed the dry density of $16 \mathrm{kN} / \mathrm{m}^{3}$ and moisture content of 10,15 , and $20 \%$. The odometer examined the samples' swelling and compression in both pure and acidic water. Characterization tests i.e., XRF, XRD, and FTIR were also performed. The results showed that swelling and compression were affected by initial moisture and bentonite content. Samples with a moisture content of $20 \%$ showed compression in acidic water. Acidic water changed the water absorbed on the clay surface without altering the mineral. A mixture containing $20 \%$ bentonite compacted to optimum moisture content was found at best in reducing the acidic water effects.
\end{abstract}

Keywords: claystone; bentonite; swelling; compression; clay liner

\section{Introduction}

Numerous materials have been proposed as waste barriers, one of which is a mixture of claystone and bentonite. Along with the clay minerals it contains, claystone is used to recycle waste material from excavation [1]. Previously, claystone from excavation was considered as an undesirable construction material, particularly when it came into contact with water [2,3]. During the development of the Banjarbakula landfill in Banjarbaru, South Kalimantan, Indonesia, an approximately $8000 \mathrm{~m}^{3}$ of claystone was dumped for being seen undesirable. In fact, the economic and environmental concerns should be addressed from the use of this material [1] considering some economic benefits from of the utilization of this material.

Hydraulic conductivity, shear strength, compressibility and swelling characteristics are some of the properties commonly evaluated in relation to the use of bentonite-based materials as a landfill barrier. These properties are strongly influenced by the bentonite content in the mixture. Khalid et al. [4] found that the influence of bentonite on the geotechnical properties was more evident at a bentonite percentage of more than $10 \%$ for clay-bentonite mixture. Meanwhile, adding more than $20 \%$ bentonite to silty sand had no effect on the hydraulic conductivity of the clay liner [5].

Clay liners, as a barrier, are extremely prone to interact

* Corresponding author. Tel.: +62-511-4773858; fax: +62-511-4773858 Email: y.arifin@ulm.ac.id

https://doi.org/10.21924/cst.6.2.2021.540 with substances other than water. In the nuclear waste repository, the sealing material will interact with the saline solution of the surrounding host rock. This will bring an effect on the canister's corrosion, the swelling and self-sealing capability of the bentonite back fill, and a sophisticated geochemical calculation [6]. Wang et al. [1] found that, due to the high sample density and low salinity of the water utilized, water chemistry had no effect on the swelling behavior of compacted claystone-bentonite mixs. The swelling pressure of compacted claystone-bentonite mixture is affected by the final dry density of bentonite in the mixture, while the claystone used is considered to behave as sand [1].

Claystone, on the other hand, is highly impacted by the minerals it contains. Its combination with bentonite will bring effect on the mixture's behavior overall. The swelling capacity of bentonite is also determined by the chemistry of saturating fluids; the higher the salinity, the lower the sample's swelling capacity in which has a negligible effect on samples with a high density (i.e. $17-19 \mathrm{kN} / \mathrm{m}^{3}$ ) [1].

Besides density, water salinity has an effect on hydromechanical materials containing a large amount of smectite (i.e. 50\% bentonite) [6]. Apart from swelling characteristics, Siddiqua et al. [6] examined the influence of salt on compression and swelling indices (i.e., $c_{c}$ and $c_{s}$ ) obtained by consolidation tests. $c_{c}$ was found to decrease in the presence of saline solution, indicating its influence on the sample's compressibility behavior. On natural stiff clay, the similar results were reported by Ngunyen et al. [7]. Clays with a high smectite content experienced more alterations than 
others.

Sealing materials may also interact with acidic liquids in addition to salt. Acidic water, which is generated by acid rain and has a $\mathrm{pH}$ of 3-4.5, reduces the shear strength of sedimentary and igneous residual soils as well as increases their permeability [8]. Acid rain infiltration into the soil causes leaching of $\mathrm{Fe}^{3+}$ and $\mathrm{Al}^{3+}$, which plays an important role in cementation. The effect of acid rain on the development of soil erosion was also investigated by Matsumoto et al.[9]. The release of $\mathrm{Al}^{3+}$ owing to fluids with $\mathrm{pH}$ of 2-6 was also observed in the study in which it resulted in the development of soil erosion. Meanwhile, Ahmed et al. [10] found that the swelling ratio reduced when the $\mathrm{pH}$ in soil pores decreased due to acid water. Gratchev and Towhata [11] investigated the potential of changes in the compressibility of marine clay due to soil contamination from the past waste mismanagement. It is reported that acid water increases or decreases the compressibility index dependent upon the minerals and soil structure. Le et al. [12] investigated a coastal acid sulfate soil in Australia containing sulfidic mineral (i.e., $\mathrm{FeS}_{2}$ ). The results of the compressibility test showed that the physical structure of the soil was determined by $\mathrm{H}^{+}$and $\mathrm{Ca}^{2+}$ cations. In a short time, the effect appeared to be insignificant. Besides time, however, the combination of pore water chemical composition, compressive pressure, and moisture content affected the permeability of the acid sulfate soil [12].

Acidic water has also been reported to cause damage in industrial areas for being contaminated with sulfuric acid, which has been widely used in paper industry, petroleum refining, copper leaching, inorganic pigments, and organic chemical industry [13]. In the soil, it was found that $1 \mathrm{~N}$ $\mathrm{H}_{2} \mathrm{SO}_{4}$ resulted in the formation of gypsum and cornelite, whereas $4 \mathrm{~N} \mathrm{H}_{2} \mathrm{SO}_{4}$ formed aluminite and chloritoid. Mineral changes in the black cotton soil used in the study resulted in an increase in percent swelling. In addition, acid solution with a higher concentration also produced a greater swelling potential [13]. Numerous researchers have also reported soil heaving induced by acidic solutions [14]-[16]. Sridharan et al. [14] studied the incidence of floor, pavement and foundation distress in a fertilizer factory. The damage was determined to be the result of heave induced by phosphoric acid reacting with soil in an acidic environment. Assa'ad [15] reported the incline of the storage tank at the chemical fertilizer factory in Aqaba, Jordan was caused by phosphoric acid leaking and interacting with the subgrade soil. Like a gel, phosphate compounds are formed and fill the pores, which generate the trapped gases from the chemical process. The generated pressure causes the tank to lift when it is empty. Rama Vara Prasad et al. [17] investigated the swelling potential of three soils, namely black cotton soil, sodium bentonite, and kaolinite, using two acidic solutions (i.e., $\mathrm{H}_{2} \mathrm{SO}_{4}$ and $\mathrm{H}_{3} \mathrm{PO}_{4}$ ). The results then showed that the swelling potential of montmorillonite soils was determined by the type of cation exchangeable. The cation exchange reaction and the dissolution of some minerals resulted in mineral changes in the montmorillonite soil, which affected its swelling behavior. In kaolinite soils, the adsorption of $\mathrm{H}^{+}$at the broken ends resulted in a face-to-edge association of the particle, which caused an increase in the swelling potential of the soil, coupled with changes in soil mineralogy. Chen et al. [18] investigated the compressibility of kaolinite soil using pore fluid with a dielectric constant larger than water, such as acetic acid. The results indicated that the compression and swelling index samples in the solution were smaller than that of in water. Meanwhile, Wahid et al. [19] concluded that kaolinite is not affected by salinity but $\mathrm{pH}$, which attacks the tip of the particle. The compression that occurs under constant load is caused by the interaction of kaolinite with acid solution as a result of sliding between particles and is irreversible.

In South Kalimantan, the area is predominantly swampy and low land. In areas where the soil is predominantly peat, the presence of sulfuric acid in river water causes the $\mathrm{pH}$ to vary from 3.4-4.2. The $\mathrm{pH}$ does not increase even during rainy season due to high precipitation resulting in increasing water levels in the river, thereby preventing the entry of seawater into the river [20]. This can occur in any locations with a large area of peat wetland. Tcvetkov [21] provided data in countries with peat swamp areas, including Russia (150 million ha), Indonesia (26 million ha), the United States of America (40 million ha), Canada (170 million ha), Finland (10 million ha), China (3.5 million ha), Sweden ( 7 million ha), and Ireland (1.2 million ha), as well as the remaining 12.3 million ha in Malaysia, Germany, Poland, the United Kingdom, and Belarus. Wind-Mulder et al. [22] reported that water chemistry data from four peat swamp areas in Canada showed the average $\mathrm{pH}$ of 3.7-3.9 with a predominant of $\mathrm{SO}_{4}{ }^{2-}$. Therefore, the acidic water has a high potential of reacting with the clay liner surrounding it. This paper aims to examine the effect of swamp acidic water on the volume change (i.e., swelling and compression) of the claystone-bentonite mixture. An odometer was used to evaluate samples of claystone and bentonite mixtures with various compositions in acid water as immersion.

\section{Materials and Methods}

This study used both natural and fabricated clays (i.e., claystone and bentonite). Meanwhile, the acidic water utilized was directly obtained from a swampy area to explore its composition and effects on the clay liner. Overall sample preparation, compaction, and volume change tests were carried out in the laboratory at room temperature.

\subsection{Claystone}

The claystone used was taken from the Banjarbakula landfill project site. The soil however not used in the project and was disposed of. The claystone had a moisture content of 2.76\%, Gs 2.6, a liquid limit (LL) of 40\%, a plastic limit (PL) of $20 \%$, and a shrinkage limit (SL) of $15 \%$. The material meanwhile consisted of $4.5 \%$ sand, $43.9 \%$ silt, and $51.6 \%$ clay. According to the Unified Soil Classification System (USCS) [23], the claystone is classified as an inorganic clay with low to medium plasticity (CL). The main exchangeable cation claystone used was $\mathrm{Ca}^{2+} 4.3 \mathrm{meq} / \mathrm{g}$ and the remainder was $\mathrm{Na}^{+} 0.3 \mathrm{meq} / \mathrm{g}, \mathrm{Mg}^{2+} 0.1 \mathrm{meq} / \mathrm{g}$, and $\mathrm{K}^{+} 0.3 \mathrm{meq} / \mathrm{g}$. At a dry unit weight of $16 \mathrm{kN} / \mathrm{m}^{3}$, the compacted claystone had a hydraulic conductivity of $7.9 \times 10^{-9} \mathrm{~m} / \mathrm{s}$ [24]. This value is greater than the one required for clay liners in many countries (i.e., $1.0 \times 10^{-9} \mathrm{~m} / \mathrm{s}$ ) [25]. 


\subsection{Bentonite}

The bentonite used was commercial one with the main exchangeable cation of $\mathrm{Ca}^{2+} 18.7 \mathrm{meq} / \mathrm{g}$ and the others (i.e., $\mathrm{Na}^{+}, \mathrm{Mg}^{2+}$, and $\mathrm{K}^{+}$) were $0.34 \mathrm{meq} / \mathrm{g}, 0.2 \mathrm{meq} / \mathrm{g}$, and 0.58 $\mathrm{meq} / \mathrm{g}$, respectively. The bentonite had a moisture content of $14.17 \%$, a specific gravity of 2.71 , LL $351.71 \%$, PL $44.68 \%$, SL $41.89 \%$, and a plasticity index (PI) of $307.03 \%$. The material meanwhile consisted of $1.4 \%$ fine sand, $8.3 \%$ silt, and $90.3 \%$ clay.

\subsection{Acidic water}

Acidic water was taken from a river in Tanipah village, in Barito Kuala district in South Kalimantan. The water had a $\mathrm{pH}$ of 3.4-3.6. This $\mathrm{pH}$ tends to remain constant throughout the year in both the dry and rainy seasons. Table 1 presents the chemical composition of the acidic water.

The chemical compounds dominant in the solution included $\mathrm{Ca}^{2+}, \mathrm{SO}_{4}{ }^{2-}$, and $\mathrm{Cl}^{-}$. The high concentration of sulfate ions was as a result of pyrite oxidation occurred in the soil [20]. Commonly, the $\mathrm{SO}_{4}{ }^{2+} / \mathrm{Cl}^{-}$ratio is used to determine the influence of sulfuric acid on pyrite oxidation on the composition of river water in swamp areas.

Table 1. Chemical compositions of the acidic water used.

\begin{tabular}{cccccccc}
\hline $\begin{array}{c}\text { Chemical } \\
\text { compound }\end{array}$ & $\mathrm{K}^{+}$ & $\mathrm{Ca}^{2+}$ & $\mathrm{Na}^{+}$ & $\mathrm{Fe}^{3+}$ & $\mathrm{Mn}^{2+}$ & $\mathrm{SO}_{4}^{2-}$ & $\mathrm{Cl}^{-}$ \\
\hline $\mathrm{mg} / \mathrm{l}$ & 4.21 & 158.86 & 6.910 & 4.876 & 1.427 & 261.02 & 153.4 \\
\hline
\end{tabular}

\subsection{Sample preparation}

Bentonite was mixed with claystone at a percentage of $5 \%$, $10 \%, 15 \%$, and $20 \%$ based on its dry weight. Water was then added to the mixtures at a certain amounts to provide the samples as the initial moisture contents $(w)$ of $10 \%, 15 \%$, and $20 \%$. The sample target water contents were based on the results of the Proctor standard compaction test on the claystone with an optimum moisture content (OP) of $15 \%$ obtained. As a result, the water contents of $10 \%$ and $20 \%$ fell on the dry of optimum (DOP) and the wet of optimum (WOP) water content, respectively. Subsequently, the mixtures were statically compressed with a hydraulic jack to produce the samples of dry unit weight $\left(\gamma_{d}\right)$ of $16 \mathrm{kN} / \mathrm{m}^{3}$. The samples had a diameter of $63.4 \mathrm{~mm}$ and a height of $20 \mathrm{~mm}$. Table 2 illustrates the initial conditions and sample identifications (Sample IDs). The names have been given following the sample conditions, such as composition and initial water content.

\subsection{Swelling and Compression tests}

Two tests were carried out in the odometer, namely the swelling potential and the compression tests. These tests were performed based upon the standard ASTM procedures (i.e., ASTM D4829-11 [26] and ASTM D2435-04 [27]). The water used in the test was pure water with a $\mathrm{pH}$ of \pm 7 and swamp acidic water with a $\mathrm{pH}$ of 3.4. The tests using the two waters were carried out separately. For the test with pure water, the sample in the odometer was immersed in the water under a pressure of $6.9 \mathrm{kPa}$ to obtain the sample's swelling strain. After equilibrium was reached in which it was observed from constant dial gauge readings, the sample was loaded and subsequently unloaded in accordance to the consolidation test procedure [27]. Similar procedures were also carried out for the samples tested using swamp acidic water.

\subsection{Sample characterization}

The investigation on the effects of acidic water on the mixtures of claystone and bentonite commences with the Atterberg limit tests was carried out to determine the liquid limit, plastic limit, and plasticity index of the samples. Similar approach has been also adopted by a number of other researchers $[8,17,28]$.

Table 2. Sample initial conditions

\begin{tabular}{lcccc}
\hline Sample ID & $\begin{array}{c}\text { Claystone } \\
(\%)\end{array}$ & $\begin{array}{c}\text { Bentonite } \\
(\%)\end{array}$ & $\begin{array}{c}\gamma_{d} \\
\left(\mathrm{kN} / \mathrm{m}^{3}\right)\end{array}$ & $\begin{array}{c}w \\
(\%)\end{array}$ \\
\hline $100 \mathrm{C}-10$ & 100 & 0 & 16 & 10 \\
$100 \mathrm{C}-15$ & 100 & 0 & 16 & 15 \\
$100 \mathrm{C}-20$ & 100 & 0 & 16 & 20 \\
$95 \mathrm{C} 5 \mathrm{~B}-10$ & 95 & 5 & 16 & 10 \\
$95 \mathrm{C} 5 \mathrm{~B}-15$ & 95 & 5 & 16 & 15 \\
$95 \mathrm{C} 5 \mathrm{~B}-20$ & 95 & 5 & 16 & 20 \\
$90 \mathrm{C} 10 \mathrm{~B}-10$ & 90 & 10 & 16 & 10 \\
$90 \mathrm{C} 10 \mathrm{~B}-15$ & 90 & 10 & 16 & 15 \\
$90 \mathrm{C} 10 \mathrm{~B}-20$ & 90 & 10 & 16 & 20 \\
$85 \mathrm{C} 15 \mathrm{~B}-10$ & 85 & 15 & 16 & 10 \\
$85 \mathrm{C} 15 \mathrm{~B}-15$ & 85 & 15 & 16 & 15 \\
$85 \mathrm{C} 15 \mathrm{~B}-20$ & 85 & 15 & 16 & 20 \\
$80 \mathrm{C} 20 \mathrm{~B}-10$ & 80 & 20 & 16 & 10 \\
$80 \mathrm{C} 20 \mathrm{~B}-15$ & 80 & 20 & 16 & 15 \\
80C20B-20 & 80 & 20 & 16 & 20 \\
\hline
\end{tabular}

The acidic water has a physical influence on clay and can cause chemical and mineral changes with the clay. The alterations in the mineral contents were investigated using Xray diffraction (XRD) analysis for the samples before and after the test with the acidic water. In addition, Fouriertransform infrared spectroscopy (FTIR) test was used to analyze the functional groups of materials tested with pure water and acidic water. Finally, the samples' chemical compositions were measured using X-ray fluorescence (XRF).

\section{Results and Discussions}

\subsection{Effect of swamp acidic water on sample characterization.}

Figs. 1(a) and 1(b) depict the influence of acidic water on the claystone-bentonite mixture's liquid limit (LL) and plastic limit (PL), respectively. Figure 1(a) shows that LL increased with the increasing bentonite concentration in both the pure water and acidic water tests. This was plausible since the LL of the bentonite was found greater than that of the claystone. It is also evident that the influence of bentonite content on the 
LL was observed at the bentonite concentrations greater than $10 \%$. This finding is consistent with what was reported by Khalid et al. [4], who found that bentonite had an impact on the clay-bentonite combination at a concentration of higher than $10 \%$. The LL of the samples tested with the acidic water was consistently greater than those tested with pure water
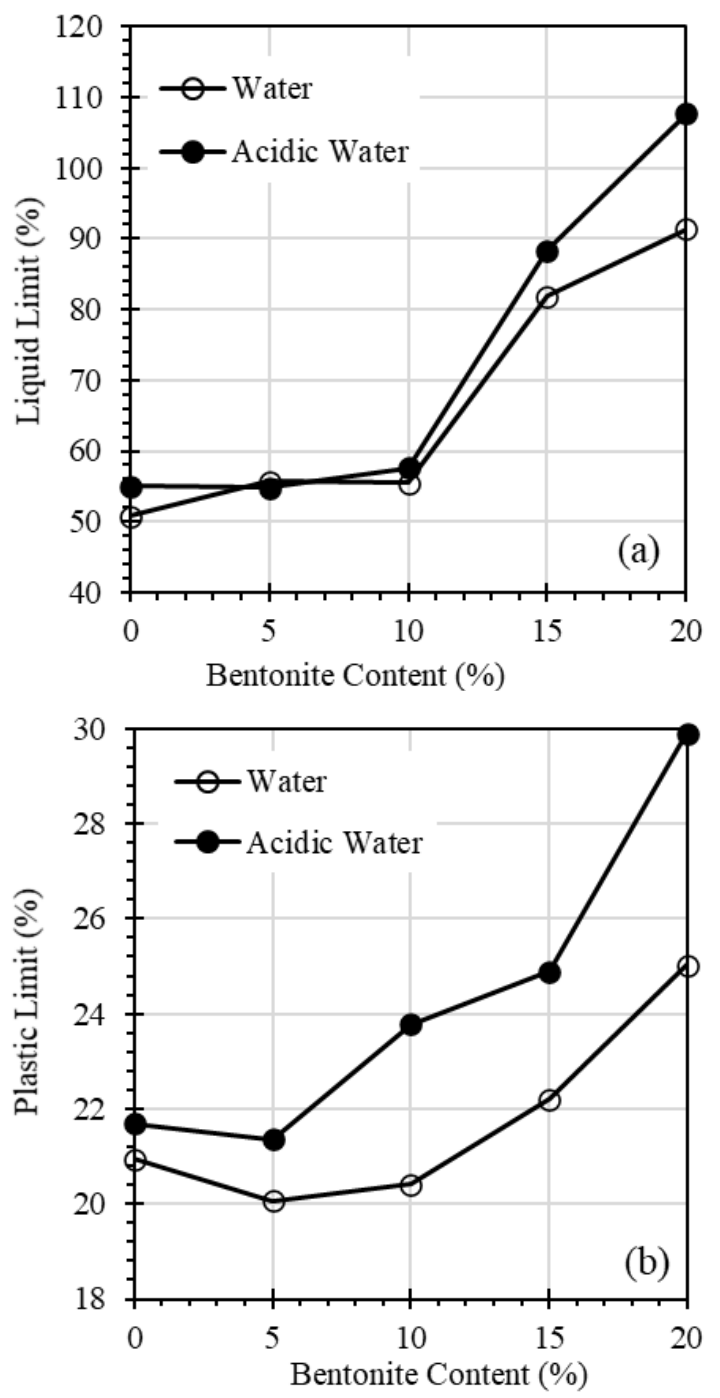

Fig. 1. Effect on acidic water on liquid limit and plastic limit of claystone-bentonite mixtures

containing more than $10 \%$ bentonite, as shown in Figure 1(a). LL increased up to $16 \%$ at the $20 \%$ bentonite content. At the same bentonite content, LL was also found higher up to $16 \%$ for the samples tested in the acidic water. An insignificant increase in the PL was also observed when testing the samples with the acidic water. The greatest difference in the PL of around $5 \%$ was shown at the $20 \%$ bentonite content. Since only minor change in the PL was observed for the tests using the acidic water, the change in the PI was almost similar to the change in the LL. An increase in the LL and PI with reducing $\mathrm{pH}$ of the soil water was also reported by Bakhshipour et al. [8].

Table 3 shows the oxides contents of claystone, bentonite, and claystone-bentonite mixtures before and after interacting with the acidic water obtained from the XRF test. The samples tested were taken from those after the consolidation test with different bentonite and initial water contents. According to samples ID, the samples consisted of claystone, bentonite, and the mixes with varying bentonite percentages (i.e., 5\% (95C5B) and 20\% (80C20B)), and different initial moisture contents (i.e., $10 \%$ and 20\%). As shown in the table 3, claystone and bentonite predominately contained $\mathrm{SiO}_{2}$ with a percentage of $55.6 \%$ and $54.6 \%$, respectively, followed by $\mathrm{Fe}_{2} \mathrm{O}_{3}$ as the next oxide with a content of $19.3 \%$ and $23.4 \%$, respectively. Both materials also contained almost equal $\mathrm{Al}_{2} \mathrm{O}_{3}$, which is $15 \%$ and $14 \%$, respectively. The rests were $\mathrm{K}_{2} \mathrm{O}, \mathrm{CaO}$ and $\mathrm{TiO}_{2}$.

Table 3. Oxides of claystone, bentonite, dan claystone--bentonite mixtures

\begin{tabular}{|c|c|c|c|c|c|c|c|}
\hline \multirow{2}{*}{ Sample ID } & \multirow{2}{*}{ Condition } & \multicolumn{6}{|c|}{ Compound (\%) } \\
\hline & & $\mathrm{Al}_{2} \mathrm{O}_{3}$ & $\mathrm{SiO}_{2}$ & $\mathrm{~K}_{2} \mathrm{O}$ & $\mathrm{CaO}$ & $\mathrm{TiO}_{2}$ & $\mathrm{Fe}_{2} \mathrm{O}_{3}$ \\
\hline Claystone (C) & $\begin{array}{l}\text { Before } \\
\text { the test }\end{array}$ & 15 & 55.6 & 4.33 & 3.22 & 1.83 & 19.3 \\
\hline Bentonite (B) & $\begin{array}{l}\text { Before } \\
\text { the test }\end{array}$ & 14 & 54.6 & 0.56 & 4.10 & 1.82 & 23.4 \\
\hline $95 \mathrm{C} 5 \mathrm{~B}-10$ & $\begin{array}{l}\text { After the } \\
\text { test }\end{array}$ & 14 & 55.1 & 3.90 & 2.98 & 1.91 & 21.2 \\
\hline 95C5B-20 & $\begin{array}{l}\text { After the } \\
\text { test }\end{array}$ & 14 & 53.8 & 4.01 & 3.01 & 1.93 & 21.4 \\
\hline $80 \mathrm{C} 20 \mathrm{~B}-10$ & $\begin{array}{l}\text { After the } \\
\text { test }\end{array}$ & 13 & 54.8 & 3.43 & 3.17 & 1.93 & 22.6 \\
\hline $80 \mathrm{C} 20 \mathrm{~B}-20$ & $\begin{array}{c}\text { After the } \\
\text { test }\end{array}$ & 14 & 53.1 & 3.41 & 3.33 & 1.90 & 22.6 \\
\hline
\end{tabular}

Bakhshipour et al. [8] reported the leaching of $\mathrm{Al}^{2+}, \mathrm{Fe}^{3+}$, $\mathrm{Si}^{2+}, \mathrm{K}^{+}$and $\mathrm{Ca}^{2+}$ due to acid rain infiltration, which resulted in the reduced sample strength. Artificial acid rain (AAR) was prepared by adding a certain volume of $0.005 \mathrm{M}$ nitric acid $\left(\mathrm{HNO}_{3}\right)$ and sulfuric acid $\left(\mathrm{H}_{2} \mathrm{SO}_{4}\right)$ to deionized distilled water with the $\mathrm{pH}$ values of 2, 3, 4, 5, and 5.6. In this study, samples soaked in the acidic water with chemical contents as shown in table 1 did not affect the samples' oxide contents. The contents of $\mathrm{Al}_{2} \mathrm{O}_{3}, \mathrm{Fe}_{2} \mathrm{O}_{3}$, and $\mathrm{SiO}_{2}$ as shown in table 3 did not alter for the samples with $5 \%$ and $20 \%$ bentonite contents. Neither cation exchange nor leaching occurred during the swelling and consolidation processes.

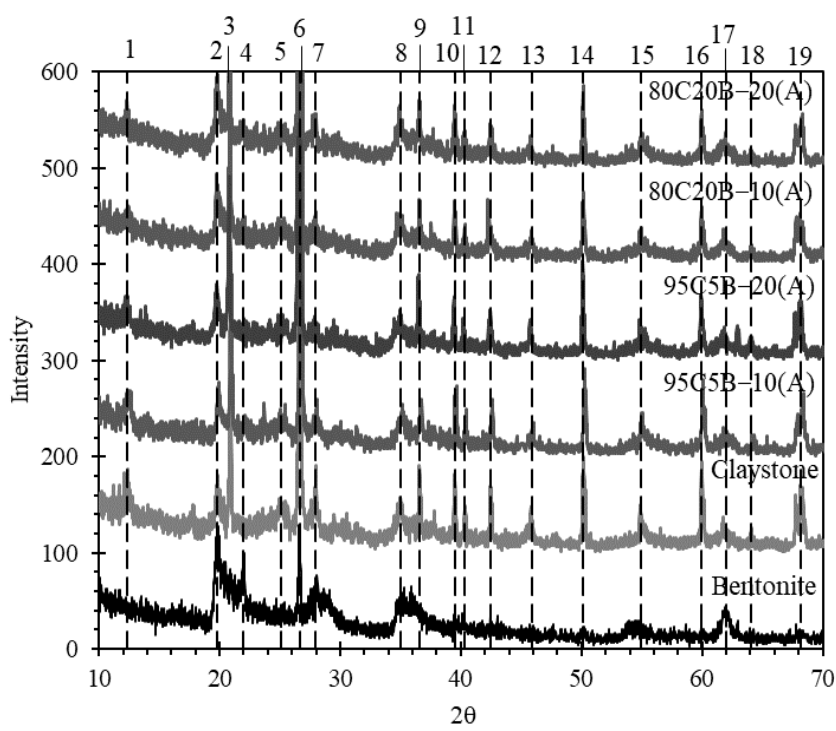

Fig. 2. Mineralogy of samples before and after tested by the acidic water

Figure 2 shows the XRD results of the claystone and bentonite samples (i.e., the bottom curve) and those after 
interacting with the acidic water (denoted by (A)) for different bentonite contents (i.e., 5\% and 20\%) and initial water contents (i.e., $10 \%$ and 20\%). As shown, the claystone sample contained more minerals than the bentonite sample, based on the number of peaks created by the XRD test. This was due to the fact that the claystone samples were collected directly from the nature without any purification or other processes. Claystone is composed of various minerals, including kaolinite (1), illite $(2,11)$, quartz $(3,6,10,12,14,19)$, vermiculite $(5,16)$, feldspar $(7)$, montmorillonite $(8,17)$, chlorite (9), mica (13), and kaolinite $(15,18)$. In bentonite numerous minerals are found, including illite (2), feldspar (4), quartz (6), and montmorillonite $(8,17)$.

Table 4 summarizes the mineral composition of the samples before and after the test, based on the XRD test results as shown in Figure 2. As seen in table 4, no minerals were dissolved or formed as a result of interacting with the acidic water solutions. This result differed from the findings of previous investigations, including Sivapullaiah et al. [13] and Rama Vara Prasad et al. [17]. This discrepancy might be explained by the low concentration and brief duration of the interaction (approximately 14 days) with the acidic water. According to Le et al. [12], the combination of acidic water concentration and interaction time has an effect on the solution's interaction with the soil. Apart from that, clay, particularly bentonite, has a very time-dependent behavior, and the clayliner used must be able to sustain contamination throughout the waste decomposition process, which can take up to 50 years, and future research will be conducted over a longer period of time.

Table 4. Sample's mineralogy before and after the test

\begin{tabular}{|c|c|c|c|c|c|c|}
\hline \multirow[b]{2}{*}{ Mineral } & \multicolumn{2}{|c|}{$\begin{array}{c}\text { Before the } \\
\text { test }\end{array}$} & \multicolumn{4}{|c|}{ After consolidation (A) } \\
\hline & 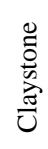 & 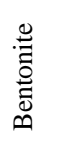 & $\begin{array}{l}0 \\
1 \\
n \\
0 \\
0 \\
n\end{array}$ & 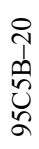 & 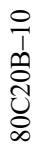 & 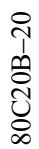 \\
\hline Illite & $\sqrt{ }$ & $\sqrt{ }$ & $\sqrt{ }$ & $\sqrt{ }$ & $\sqrt{ }$ & $\sqrt{ }$ \\
\hline Quartz & $\sqrt{ }$ & $\sqrt{ }$ & $\sqrt{ }$ & $\sqrt{ }$ & $\sqrt{ }$ & $\sqrt{ }$ \\
\hline Vermiculite & $\sqrt{ }$ & $x$ & $\sqrt{ }$ & $\sqrt{ }$ & $\sqrt{ }$ & $\sqrt{ }$ \\
\hline Feldspar & $\sqrt{ }$ & $\sqrt{ }$ & $\sqrt{ }$ & $\sqrt{ }$ & $\sqrt{ }$ & $\sqrt{ }$ \\
\hline Mont. & $\sqrt{ }$ & $\sqrt{ }$ & $\sqrt{ }$ & $\sqrt{ }$ & $\sqrt{ }$ & $\sqrt{ }$ \\
\hline Chlorite & $\sqrt{ }$ & $x$ & $\sqrt{ }$ & $\sqrt{ }$ & $\sqrt{ }$ & $\sqrt{ }$ \\
\hline Mica & $\sqrt{ }$ & $x$ & $\sqrt{ }$ & $\sqrt{ }$ & $\sqrt{ }$ & $\sqrt{ }$ \\
\hline Kaolinite & $\sqrt{ }$ & $x$ & $\sqrt{ }$ & $\sqrt{ }$ & $\sqrt{ }$ & $\sqrt{ }$ \\
\hline
\end{tabular}

Figure 3 shows the results of the FTIR test to determine the functional groups of the samples used, including their condition after interacting with the swamp acidic water. Samples with $10 \%$ and $20 \%$ bentonite contents were tested. In the figure, letters A and W signify that the samples were tested with the acidic and pure water, respectively. As seen, the peaks were found in the high wavelength region, i.e., at $1630,3402,3416$, and $3620 \mathrm{~cm}^{-1}$. Each of these peaks indicated the presence of clay minerals (i.e., $3618-3628 \mathrm{~cm}^{-1}$ ) [29]. The development of $\mathrm{OH}$ was found at $3402-3445 \mathrm{~cm}^{-1}$ which is the interlayer and intralayer of the $\mathrm{H}$ bond [30]. Saputra et al. [31] also found a montmorillonite hydroxyl $(\mathrm{OH})$ peak at $3434 \mathrm{~cm}^{-1}$. Ravindra-Reddy et al. [32] reported that this peak indicated the presence of water on the mineral surface. While at low wavelengths of $1009,695,528$, and 470 $\mathrm{cm}^{-1}$, these peaks were the peaks of the $\mathrm{SiO}_{4}$ tetrahedron [32] where at $466-470$ and $528-535 \mathrm{~cm}^{-1}$ it is an indication of the presence of clay and silica minerals.

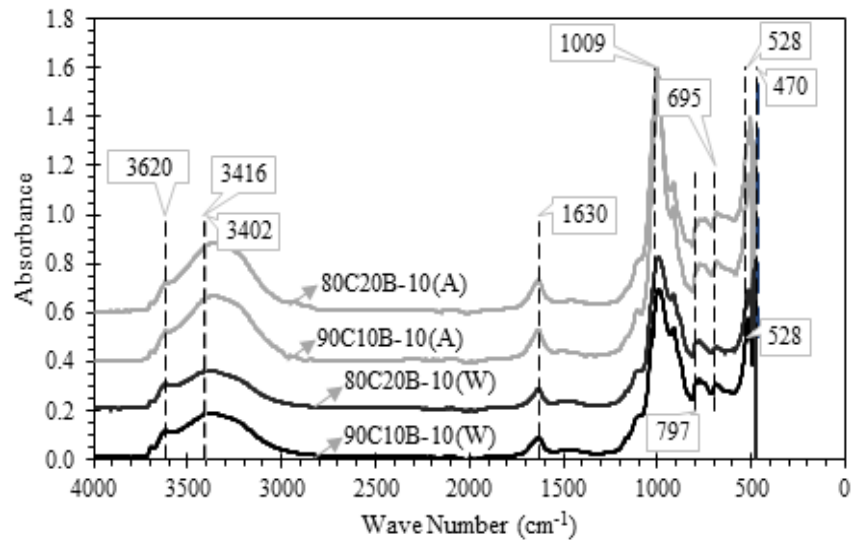

Fig. 3. Functional group of samples tested with pure water (W) and the acidic water $(\mathrm{A})$

The FTIR results confirmed that the material used had clay minerals where $\mathrm{SiO}_{4}$ was present at $3618-3628 \mathrm{~cm}^{-1}$ [29]. Moreover, the indications of the presence of the mineral montmorillonite could be seen from the development process at a wavelength of $3402-3445 \mathrm{~cm}^{-1}$ when interacting with pure water. The expansion over this range (i.e. $3402-3445 \mathrm{~cm}^{-}$ $\left.{ }^{1}\right)$ for the samples interacting with the acidic water (A) was higher than those with pure water (W). This showed that the clay surface absorbed more water when interacting with acidic water, as seen from the- $\mathrm{OH}$ extraction at a wavelength of $3402-3445 \mathrm{~cm}^{-1}$. The amount of bentonite in the mixture did not appear to affect the extraction intensity of the- $\mathrm{OH}$ samples. The impact of acid on montmorillonite was almost similar whenever the- $\mathrm{OH}$ extracting occured at a wave length between $3441 \mathrm{~cm}^{-1}$ [33] and $3427 \mathrm{~cm}^{-1}$ [34].

\subsection{Effect of swamp acidic water on swelling}

Because the test was conducted on an odometer, the only deformation occurred was in the vertical direction, without any changes in the horizontal. As a result, the amount of deformation was proportional to the volume change of the sample. Figs. 4(a)-(f) show the typical swelling development of claystone-bentonite mixtures with time when interacting with pure water (i.e., Figures. 4(a), 4(c), and 4(e)) and the acidic water (i.e., Figures. 4(b), 4(d), and 4(f)) under a $6.9 \mathrm{kPa}$ load plotted on a semi-logarithmic scale. For the sample with $10 \%$ initial moisture content as shown in figure 4(a), the deformation samples increased slowly in the early stages of the test (i.e., up to 20 minutes). Primary swelling occurred rapidly thereafter up to a certain point (i.e., up to 300-4000 minutes dependent upon the bentonite content in the mixture) slopes and reached maximum deformation. The maximum deformation recorded was referred to as the maximum swelling of the sample. The maximum swelling of claystone was reached in less than 100 minutes. Figure 4(b) shows that the initial swelling occurred gradually in the beginning, up to 20 minutes, followed by primary swelling up to 300 minutes for the samples with 5\% bentonite content, and 3000 minutes for those with $20 \%$ bentonite. The insignificant compression 

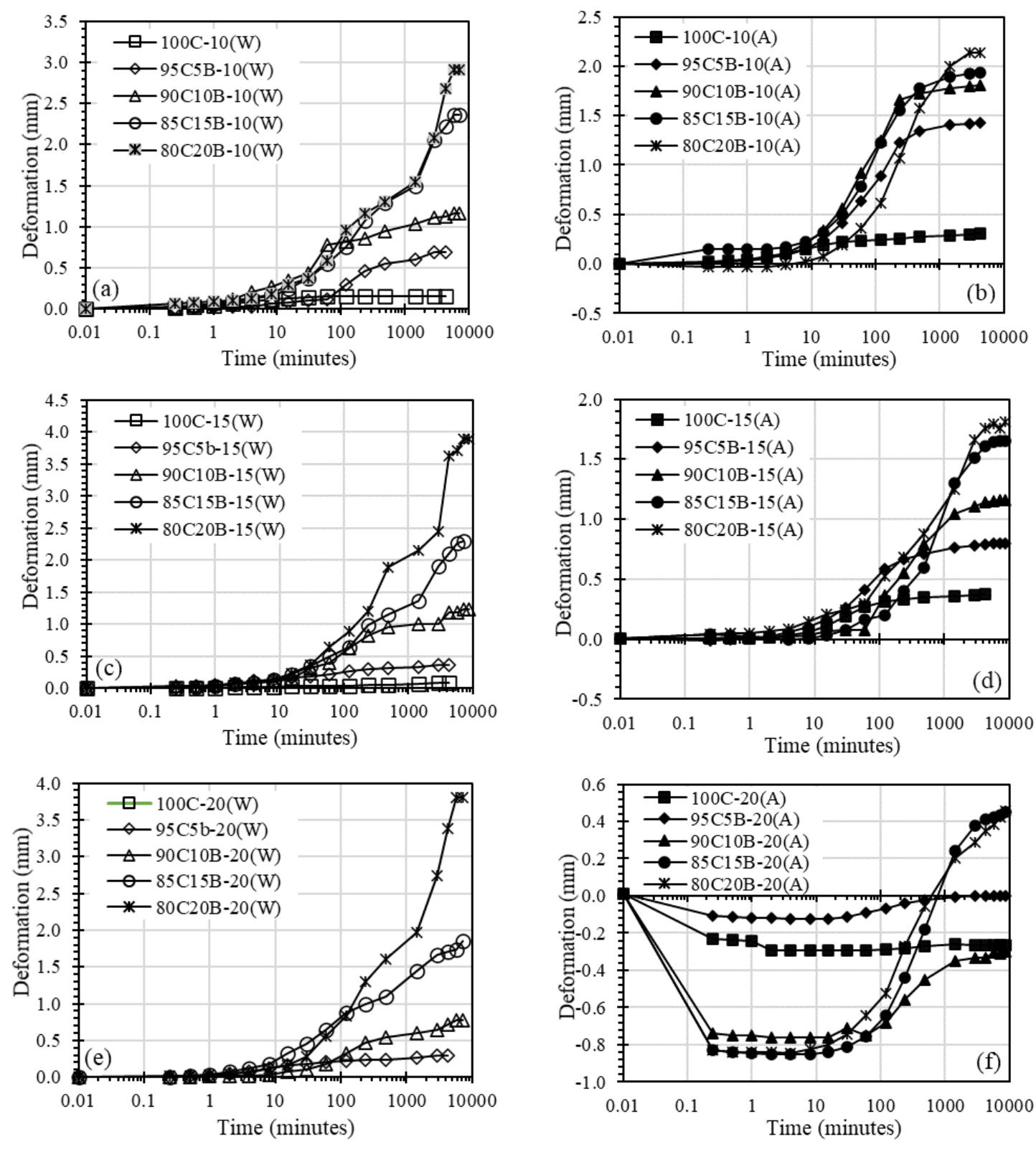

Fig. 4. Swelling development by time of claystone-bentonite mixture samples with initial moisture content of (a)-(b) $10 \%$, (c)-(d) $15 \%$, and (e)-(f) $20 \%$.

occured in sample 80C20B-10(A), which contained $20 \%$ bentonite. The same behavior was also observed in the sample with the initial moisture content of $15 \%$, as shown in figures 4(c) and 4(d).

The effect of acid water on bentonite has begun to be seen at low water content. As shown in figure 4(b), there was a significant delay in increasing deformation for 80C20B10(A), and then the sample led to the maximum deformation. The high concentration of ions contained in acidic water resulted in a balancing process with the soil water inside. As shown in FTIR in figure 3, after the acidic water began to be absorbed by the bentonite surface, modifications occurred and resulted in an increase in the amount of water absorbed on the surface. This resulted in high swelling occurred, as indicated by the vertical deformation of the sample.

Different behavior was noticed in the samples with an initial moisture content of $20 \%$, where all samples that interacted with the acidic water tended to experience shrinkage (or compression). Only two samples (i.e., 85C15B-
20(A) and 80C20B-20(A)) with $15 \%$ and $20 \%$ bentonite content, respectively, swelled back past their initial conditions. From this behavior, it can be seen that swamp acidic water has an effect on the mixtures with high bentonite content or high initial water content. Claystone containing clay minerals such as kaolinite and illite are not much affected by the acidic water. This can be seen from the results of the Atterberg limit tests (figure 1). The unremarkable effect was caused by the adsorption of $\mathrm{H}+$ at the broken end, resulting in a face-to-edge association of the particle [17,18,19].

Swelling occurs due to the absorption of water by the clay surface. It increases with the increasing percentage of bentonite in the mixture. Although both include montmorillonite, bentonite contains a greater proportion of the mineral than natural soils [35]. Thus, by adding bentonite to the mixture, the amount of montmorillonite in it increases. Clay and montmorillonite contain are thought to have a distinct influence on swelling behavior, ranging from minor to major. However, it was revealed that the latter element had a 
greater influence than the former [35]. The montmorillonite containing bentonite, according to Pusch et al [36], required 2-3 layers of water molecules to meet the hydration force. Other researchers even reported 4 layers of water molecules required [37]. The thickness and complete hydrated layers of water molecules in bentonite vary depending on its exchangeable cation. Assuming the specific surface area of bentonite is $500 \mathrm{~m}^{2} / \mathrm{g}$ and the water unit weight of $1 \mathrm{~g} / \mathrm{cm}^{3}$, Arifin [38] reported that the water content to satisfy the hydration force is $22.7 \%, 14.1 \%, 23.9 \%$, and $15.4 \%$ for the $\mathrm{Mg}, \mathrm{Ca}, \mathrm{Na}$, and $\mathrm{K}$ types of bentonite, respectively. This water content can even be greater because the surface water density is reported to be possibly more than $1 \mathrm{gr} / \mathrm{cm}^{3}$ [39]. After this water absorption, the role of surface hydration decreases. To equalize ion concentrations, water molecules tend to diffuse toward the surface.

Numerous studies have previously observed that mineral changes occur when soils, particularly those containing montmorillonite, interact with acidic solutions [13,12,17], [19]. This is not the case in this study, as shown in figure 2 and table 4 . There was even no cation exchange as shown in table 3 . The volume change occurred in the sample was due to the difference in the concentration of cations in the pore water and the acidic water. This process is known as osmoticallyinduced consolidation or osmotic consolidation [40,41]. The high concentration of cations in the acidic water (table 1) results in the outward flow from within to balance these conditions. When the water content of the sample is high, the concentration of cations in the pore water decreases and tends to release water, which results in a decrease in the soil volume (figure 4(f)).
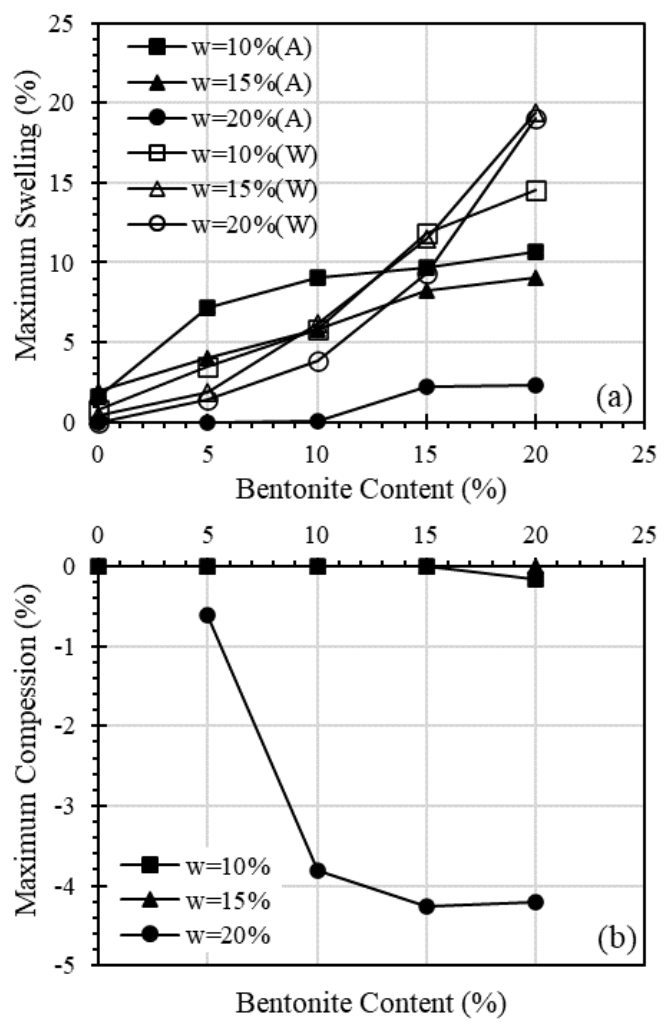

Fig. 5. (a) Maximum swelling and (b) maximum compression as a function bentonite content.

The results of the maximum percentage of swelling and compression occurred in the sample (figure 4 ) are summarized in figure. 5. Figure 5(a) shows the 10 percent bentonite level to be the limit of the distinct swelling behavior of the samples. For bentonite less than $10 \%$, the swelling in the acidic water is higher than that of in pure water for the samples with an initial water content of $10 \%$ and $15 \%$. In this condition, the behavior of claystone containing kaolinite is more dominant. In kaolinite soils, acidic water will affect the tip of the particle, resulting in a face to edge association, which results in a higher swelling potential $[17,18,19]$. At the higher bentonite contents (i.e., 15 and 20\%) where the hydration force is higher, the swelling is greater than with the acidic water when the sample interacts with pure water.

At $20 \%$ moisture content, the sample compression is higher compared to the swelling. Even at a bentonite content of less than $15 \%$, the sample tends to compress. This compression is problematic when occurs horizontally as it results in cracks $[42,43]$. During lateral compression, the shear strength of the soil decreases and its permeability increases. This behavior needs to be considered in determining an acceptable zone as a clay liner in a landfill application.

These findings are consistent with the results obtained from the FTIR test, where the samples 90C10B-10(A) and 80C20B10(A) had higher peaks, especially at a wavelength of $3402-3445 \mathrm{~cm}^{-1}$ (figure 3). At this wavelength, the samples absorbed more $-\mathrm{OH}$, so that the swelling was high (90C10B$10(\mathrm{~A})$ ) as shown in figure 5(a). Meanwhile, the swelling seemed to be smaller in the 80C20B10(A) sample compared to the one in the $80 \mathrm{C} 20 \mathrm{~B} 10(\mathrm{~W})$ sample (figure 5(a)) owing to compression, as seen in figure 5(b).

\subsection{Effect of swamp acidic water on compression of sample}

Figures 6(a)-6(d) show the results of the consolidation test in normalized void ratio versus logarithmic pressure for samples with bentonite content of 5, 10, 15, and $20 \%$, respectively. The normalized void ratio was used so that the effect of bentonite content and acidic water on the initial void ratio after swelling could be excluded in the assessment. Each sample's initial void ratio was added with a number to start at 1.0. For the same sample, the number was appended to all of the void ratio data. In general, it can be seen that the volume change indicated by the largest change in void ratio occurred in the sample with an initial moisture content of $10 \%$. This was due to the orientation of clay particles, which tended to fluctuate at low water contents and the dominant formation of macropores [38]. Macropores, or interaggregate pores, are pores that exist between soil aggregates. When the sample is compressed, the part that is greatly reduced is macropores [44].

The results in figure 6 also showed that the sample compacted at $10 \%$ water content interacted with the acidic water to produce the largest volume change. However, when compared to the one tested in the pure water, this change was still smaller. In the acidic water with higher concentrations, the intergranular attraction force increased so that the particles tended to flocculate [28]. Resistance to external forces became greater and resulted in lower compressibility. This result was supported by the FTIR test as shown in figure 3. The sample tested with the acidic water showed more -OH extraction at a wavelength of $3402-3445 \mathrm{~cm}^{-1}$ due to the low compression leaving more water on the surface of the clay minerals. 

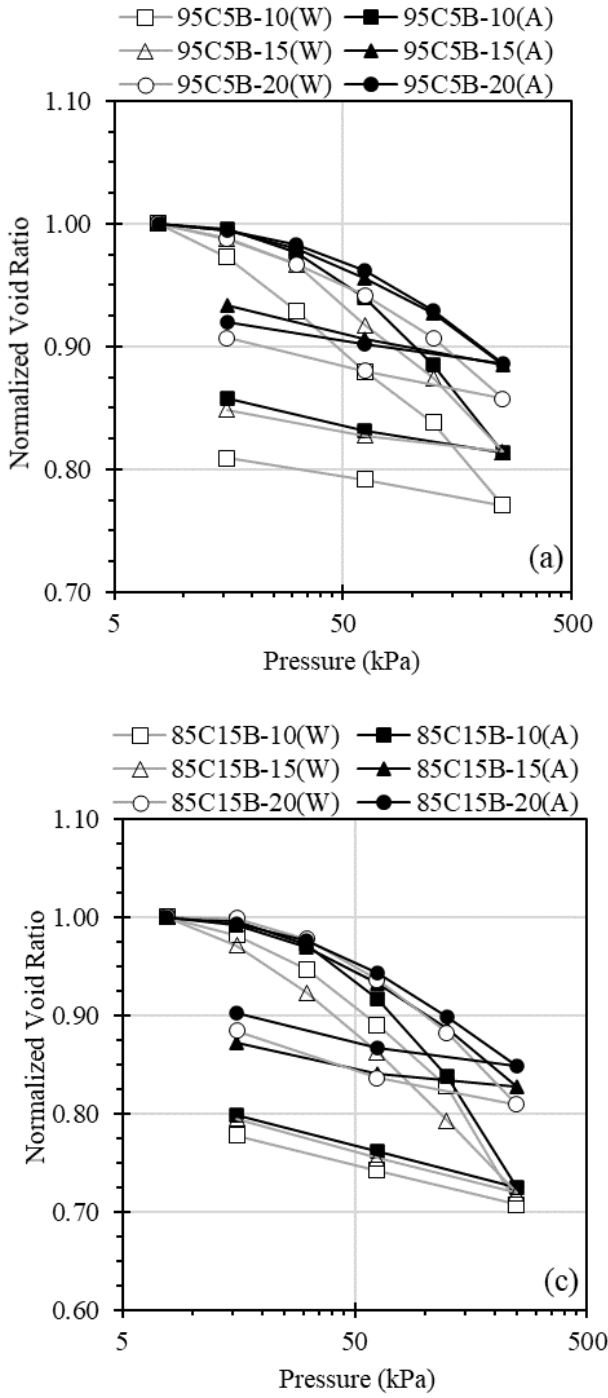
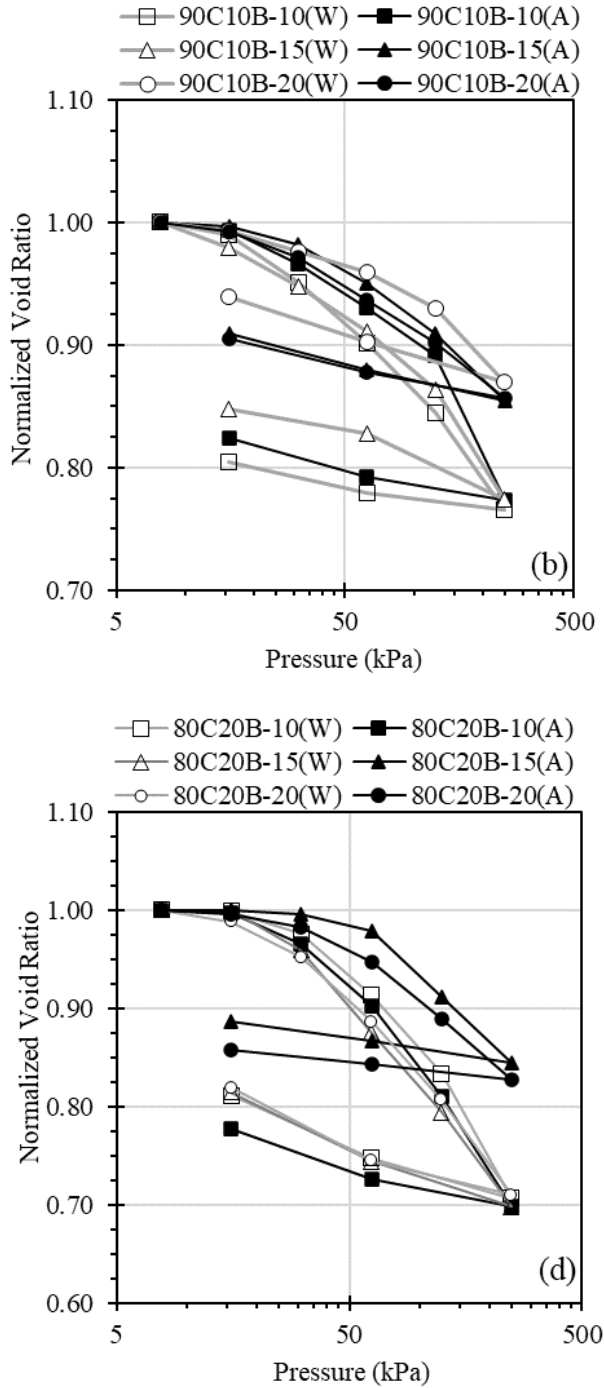

Fig. 6. Figure Normalized void ratio-logaritmic pressure relationship of compacted claystone-bentonite mixtures for Samples with (a) $5 \%$ bentonite, (b) $10 \%$ bentonite, (c) $15 \%$ bentonite, and (d) $20 \%$ bentonite. (Note: W=pure water, $A=$ the acidic water).

Figs. 7(a) and 7(b) show the coefficient of compression $\left(c_{c}\right)$ and swelling index $\left(c_{s}\right)$ of the claystone-bentonite mixtures interacting with pure water $(\mathrm{W})$ and the acidic water $(\mathrm{A})$. In general, it can be seen that $c_{c}$ increased with the increasing bentonite content. In addition, the samples with lower initial moisture contents exhibited higher $c_{c}$ regardless of the solution in which the consolidation test was performed. The effect of acidic water on $c_{c}$ was seen in the samples with an initial water content of $10 \%$, whereas for those with $15 \%$ and $20 \%$ water content, the $c_{c}$ from the tests in the acidic water was smaller than that of in pure water.

Gratchev and Towhata [11] reported that the effect of acidic water on soil compressibility is influenced by minerals, soil structure, and diffuse double layer. When interacting with acidic water, in certain soils, mineral leaching occurs, resulting in high compressibility. Changes in soil mineralogy were not found in this study, as shown in figure 2 and table 4 . At bentonite contents up to $10 \%$, where the dominant behavior of bentonite was not maximum, soil structure tended to be more flocculated when interacting with the acidic water due to the adsorption of $\mathrm{H}^{+}$at the tip of the soil particles [17] $[18,19]$. Such a structure resulted in a large amount of compressibility. However, when bentonite effect began to be prevalent i.e. at the percentage of more than $10 \%$, the $c_{c}$ value decreased due to the collapse of the diffuse double layer [ 45 ,
$11]$.

As with the $c_{c}$ value, for the compression in pure water, $c_{s}$ also increased with the increasing bentonite content in the mixture. At the same bentonite content, $c_{s}$ for the sample with higher initial water contents tended to produce higher $c_{s}$ value due to the high repulsion between sample particles. Different results have been seen in the tests with the acidic water, where at high bentonite contents (i.e., 20\%), $c_{s}$ value decreased for samples prepared at high initial water contents (i.e., $15 \%$ and $20 \%$ ) tended to decrease due to the collapse of the diffuse double layer structure.

Besides the magnitude of volume change parameters presented by $c_{c}$ and $c_{s}$, the time effect needs to be given consideration. This can be presented by the coefficient of consolidation $\left(c_{v}\right)$. Figure 8 shows the variation in $c_{v}$ values as a function of bentonite content. In general, $c_{v}$ decreases with the increasing bentonite content. This condition is increasingly seen at high bentonite contents, which is caused by the reduced sample permeability as the pores between claystone are filled with bentonite [46]. At the same bentonite content, the sample with a higher moisture content has a smaller $c_{v}$. This indicates the dominance of micropores in the behavior of the compacted mixtures $[38,44]$ at low permeability.

For the tests in the acidic water, a higher $c_{v}$ was seen at the 

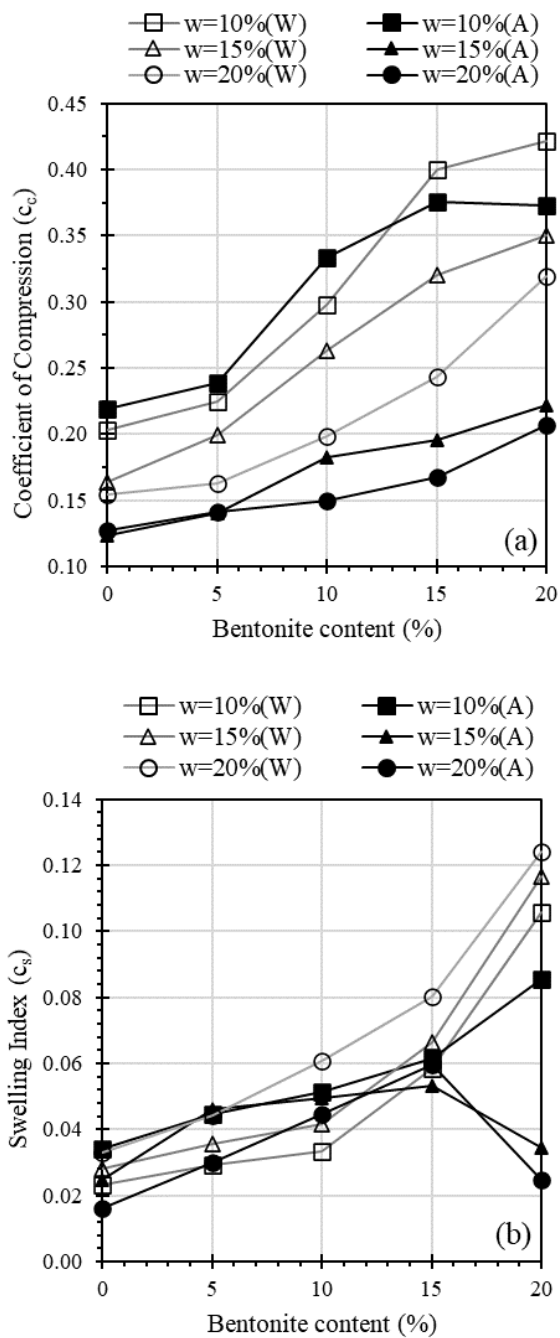

Fig. 7. Effects of acidic water on the compression parameters as a function of bentonite content (a) Coefficient of compression, and (b) swelling index.

same bentonite content when compared with the tests in pure water. This was observed especially at low bentonite contents, where flocculation of particles occurred due to clay interacting with the acidic water. This resulted in greater permeability and thus accelerated the consolidation process. As mentioned above, the bentonite content was higher than $10 \%$ where the diffuse double layer was dominant. The distance between the particles tended to be small due to the drop of the diffuse double layer sample that interacted with the acidic water. This caused the consolidation process more prolonged.

Arifin et al [24] recommended an acceptable zone of claystone-bentonite mixtures considering their permeability and shear strength. The widest zone is for the mixture with $20 \%$ bentonite content, which covers almost the entire area, both the wet of optimum (WOP) zone (i.e., w=20\%) and the dry of optimum (DOP) zone (i.e., $\mathrm{w}=10 \%$ ), as shown in figure 9 in the dash line filled with light gray. However, other aspects, such as the potential for desiccation, resistance to chemical attack, interfacial friction with the geomembrane, and the ability to deform without cracking, should also be considered [47]. Considering the effect of the acidic water on the volume change (compression), especially in the samples with a moisture content of $20 \%$ (i.e., the WOP zone), the acceptable zone for the clay liner shown in dark gray is

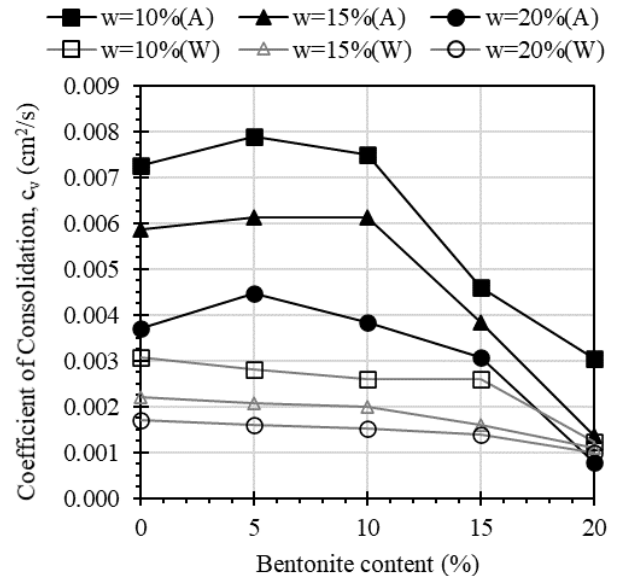

Fig. 8. Coefficient of consolidation as a function bentonite content.

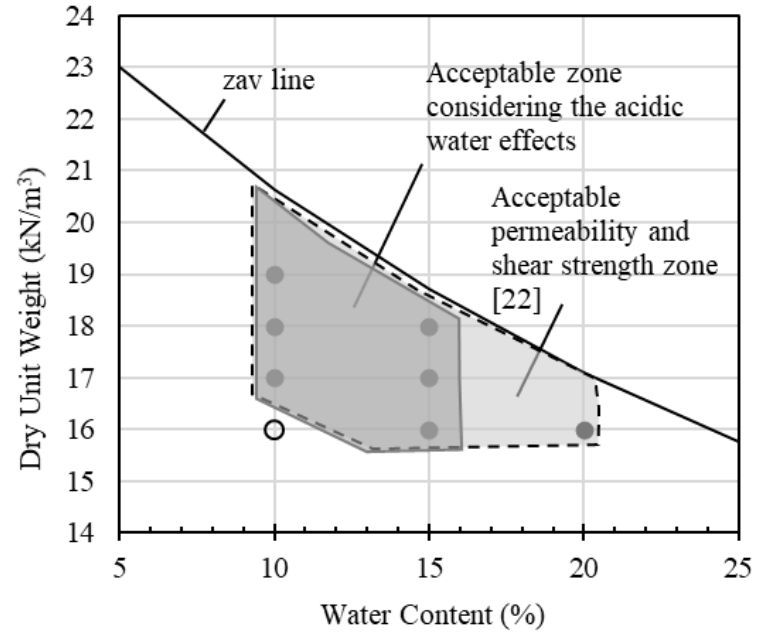

Fig. 9. Acceptable zone of claystone-bentonite mixture considering acidic water effects.

narrower than previously (figure 9).

\section{Conclusions}

The volume changes of compacted claystone-bentonite mixtures in the form of swelling and compression affected by swamp acidic water have been described and discussed. The initial moisture content of the sample affected the swelling of compacted claystone bentonite mixtures in acidic water. The sample tended to compress when the moisture level was higher than the wet of optimum. Compression increased as the amount of bentonite in the mixture increased. There was a noticeable behavioral difference between samples having more than $10 \%$ bentonite. Compression occurred faster in this condition than in pure water. A mixture with $20 \%$ bentonite content compacted at dry to optimum moisture content was found at best for mitigating the negative effects of acidic water.

\section{Acknowledgements}

The authors are grateful for the financial support provided by the University of Lambung Mangkurat through the "Dosen Wajib Meneliti" program in 2021, contract No. 009.76/UN8.2/PL/2021. 


\section{References}

1. Q. Wang, A. M. Tang, Y. J. Cui, P. Delage, and B. Gatmiri, Experimental study on the swelling behaviour of bentonite/claystone mixture, Eng. Geol. 124 (2012) 59-66.

2. I. A. Sadisun, H. Shimada, M. Ichinose, and K. Matsui, Study on the physical disintegration characteristics of Subang claystone subjected to a modified slaking index test, Geotech. Geol. Eng. 23 (2005) 199-218.

3. Z. Liu and J. Shao, Moisture effects on damage and failure of bure claystone under compression, Geotech. Lett. 6 (2016) 182-186.

4. U. Khalid, Z. ur Rehman, C. Liao, K. Farooq, and H. Mujtaba, Compressibility of Compacted Clays Mixed with a Wide Range of Bentonite for Engineered Barriers, Arab. J. Sci. Eng. 44 (2019) 5027 5042.

5. D. E. Daniel and R. M. Koerner, Compacted Soil Liners, in Quality Assurance and Quality Control for Waste Containment Facilities, U.S. Environmental Protection Agency, 1993, pp. 19-60.

6. S. Siddiqua, J. Blatz, and G. Siemens, Evaluation of the impact of pore fluid chemistry on the hydromechanical behaviour of clay-based sealing materials, Can. Geotech. J. 48 (2011) 199-213.

7. X. P. Nguyen, Y. J. Cui, A. M. Tang, Y. F. Deng, X. L. Li, and L. Wouters, Effects of pore water chemical composition on the hydromechanical behavior of natural stiff clays, Eng. Geol. 166 (2013) 52-64.

8. Z. Bakhshipour, A. Asadi, B. B. K. Huat, A. Sridharan, and S. Kawasaki, Effect of acid rain on geotechnical properties of residual soils, Soils Found. 56 (2016) 1008-1020.

9. S. Matsumoto, S. Ogata, H. Shimada, T. Sasaoka, A. Hamanaka, and G. J. Kusuma, Effects of ph-induced changes in soil physical characteristics on the development of soil water erosion, Geosci. 8 (2018).

10. A. A. Ahmed, I. M. Saaid, N. A. M. Akhir, and M. Rashedi, Influence of various cation valence, salinity, $\mathrm{pH}$ and temperature on bentonite swelling behaviour, AIP Conf. Proc., vol. 1774, no. October 2016, 2016.

11. I. B. Gratchev and I. Towhata, Effects of acidic contamination on the geotechnical properties of marine soils in Japan, Proc. Int. Offshore Polar Eng. Conf. 1 (2009) 151-155.

12. T. M. H. Le, A. N. Pham, R. N. Collins, and T. D. Waite, Impact of soil consolidation and solution composition on the hydraulic properties of coastal acid sulfate soils, Aust. J. Soil Res. 46 (2008) 112-121.

13. P. V. Sivapullaiah, B. G. Prasad, and M. M. Allam, Effect of sulfuric acid on swelling behavior of an expansive soil, Soil Sediment Contam. 18 (2009) 121-135.

14. A. Sridharan, T. S. Nagaraj, and P. V. Sivapullaiah, Heaving of Soil Due To Acid Contamination., Proc. Int. Conf. Soil Mech. Found. Eng. 2 (1981) 383-386.

15. A. Assa'ad, Differential Upheaval of Phosphoric Acid Storage Tanks in Aqaba, Jordan, J. Perform. Constr. Facil., 12 (1998) 71-76.

16. P. V. Sivapullaiah, Surprising Soil Behaviour: Is It Really!!!, Indian Geotech. J. 45 (2015).

17. C. Rama Vara Prasad, P. Hari Prasad Reddy, V. Ramana Murthy, and P. V. Sivapullaiah, Swelling characteristics of soils subjected to acid contamination, Soils Found. 58 (2018) 110-121.

18. J. Chen, A. Anandarajah, and H. Inyang, Pore Fluid Properties and Compressibility of Kaolinite, J. Geotech. Geoenvironmental Eng. 126 (2000) 798-807.

19. A. S. Wahid, A. Gajo, and R. di Maggio, Chemo-mechanical effects in kaolinite. Part 2: exposed samples and chemical and phase analyses, Geotechnique. 61 (2011) 449-457.

20. A. Haraguchi, Effect of sulfuric acid discharge on river water chemistry in peat swamp forests in central Kalimantan, Indonesia, Limnology. 8 (2017) 175-182.

21. P. S. Tcvetkov, The history, present status and future prospects of the
Russian fuel peat industry, Mires Peat. 19 (2017).

22. H. L. Wind-Mulder, L. Rochefort, and D. H. Vitt, Water and peat chemistry comparisons of natural and post-harvested peatlands across Canada and their relevance to peatland restoration, Ecol. Eng. 7 (1996) 161-181.

23. ASTMD2487, Standard Practice for Classification of Soils for Engineering Purposes (Unified Soil Classification System), ASTM Int. West Conshohocken, PA, 1-5, 2006.

24. Y. F. Arifin, M. Arsyad, A. A. Pangestu, and D. Pratama, the Permeability and Shear Strength of Compacted Claystone-Bentonite Mixtures, Int. J. GEOMATE. 21 (2021) 48-61.

25. J. Chai and N. Miura, Comparing the performance of landfill liner systems, J mater cycles waste Manag. 4 (2002) 135-142.

26. ASTM D4829 - 11, Standard Test Method for Expansion Index of Soils, ASTM Int. West Conshohocken, PA, www.astm.org, 1-6, 2011.

27. ASTMD2435-04, Standard Test Methods for One-Dimensional Consolidation Properties of Soils Using Incremental Loading, Annu. B. ASTM Stand., 1-10, 2004.

28. M. Olgun and M. Yildiz, The Effects of Pore Fluids with Different Dielectric Constants on the Geotechnical Behaviour of Kaolinite, Arab. J. Sci. Eng. (2012) 1833-1848.

29. A. Georgakopoulos, A. Iordanidis, and V. Kapina, Study of low rank greek coals using FTIR spectroscopy, Energy Sources. 25 (2003) 9951005 .

30. C. M. Hristodor, N. Vrinceanu, A. Pui, O. Novac, V. E. Copcia, and E. Popovici, Textural and morphological characterization of chitosan/bentonite nanocomposite, Environ. Eng. Manag. J. 11 (2012) 573-578.

31. O. A. Saputra et al., Silylated-montmorillonite as co-adsorbent of chitosan composites for methylene blue dye removal in aqueous solution, Commun. Sci. Technol. 5 (2020) 45-52.

32. R. Reddy T, K. S, E. T, and L. Reddy S, Spectroscopic Characterization of Bentonite, J. Lasers, Opt. Photonics. 04 (2017).

33. K. G. Akpomie and F. A. Dawodu, Acid-modified montmorillonite for sorption of heavy metals from automobile effluent, Beni-Suef Univ. J. Basic Appl. Sci. 5 (2016) 1-12.

34. A. S. Özcan, B. Erdem, and A. Özcan, Adsorption of Acid Blue 193 from aqueous solutions onto BTMA-bentonite, Colloids Surfaces A Physicochem. Eng. Asp. 266 (2005) 73-81.

35. P. S. Reddy, B. Mohanty, and B. H. Rao, Influence of Clay Content and Montmorillonite Content on Swelling Behavior of Expansive Soils, Int. J. Geosynth. Gr. Eng. 6 (2020).

36. R. Pusch, O. Karnland, and H. Hökmark, GMM - A general microstructural model for qualitative and quantitative studies of smectite clays, SKB Tech. Rep. TR-90-43 (1990) 105.

37. N. Saiyouri, D. Tessier, and P. Y. Hicher, Experimental study of swelling in unsaturated compacted clays, Clay Miner. 39 (2004) 469-479.

38. Y. F. Arifin, Thermo-hydro-mechanical Behavior of Compacted Bentonite Sand Mixtures: An Experimental Study, Bauhaus Universitaet Weimar, Germany, 2008.

39. Q. Wang, Y. J. Cui, A. Minh Tang, L. Xiang-Ling, and Y. Wei-Min, Time- and density-dependent microstructure features of compacted bentonite, Soils Found. 54 (2014) 657-666.

40. S. Bulolo and E. C. Leong, Osmotic consolidation of expansive soil, 7th Asia-Pacific Conf. Unsaturated Soils, AP-UNSAT 2019. c (2019) 256260.

41. T. Thyagaraj and S. M. Rao, Osmotic Swelling and Osmotic Consolidation Behaviour of Compacted Expansive Clay, Geotech. Geol. Eng. 31 (2013) 435-445.

42. L. Tan, P. Zheng, and Q. Liu, Effects of Saline Solutions on the Desiccation Cracking and Shrinkage Behavior of Gaomiaozi Bentonite, 
Adv. Civ. Eng. 2020 (2020).

43. N. Shokri, P. Zhou, and A. Keshmiri, Patterns of Desiccation Cracks in Saline Bentonite Layers, Transp. Porous Media. 110 (2015) 333-344.

44. P. Delage, Microstructure Features in the Behaviour of Engineered Barriers for Nuclear Waste Disposal, Exp. Unsaturated Soil Mech. (2007) 11-32.

45. A. Gajo and M. Maines, Mechanical effects of aqueous solutions of inorganic acids and bases on a natural active clay, Geotechnique. 57
(2007) 687-699.

46. C.-L. Zhang, Sealing Performance of Fractured Claystone and ClayBased Materials. Gesellschaft für Anlagen- und Reaktor- sicherheit (GRS) gGmbH, 2017.

47. D. E. Daniel and C. H. Benson, Water content-density criteria for compacted soil liners, J. Geotech. Eng. 116 (1990) 1811-1830. 